\title{
Investigating the Modulatory Role of Chronological and Biological Age on Performance Predictors in Youth Swimmers
}

\author{
M. A. McNarry ${ }^{1}$ - $\cdot$ L. Lester ${ }^{2} \cdot$ J. Brown ${ }^{1} \cdot$ K. A. Mackintosh ${ }^{1}$ (D)
}

Received: 27 April 2020 / Accepted: 31 August 2020 / Published online: 27 October 2020

(c) The Author(s) 2020

\begin{abstract}
Purpose The aim of this study was to determine the modulatory roles of biological maturity and age on the predictors of performance in youth swimmers and their stability over a six-month training cycle.

Methods In total, 28 swimmers (10 pre-pubertal [ 6 boys], $11.1 \pm 1.8$ years; 18 pubertal [ 8 boys], $15.2 \pm 2.0$ years old) and 26 untrained controls ( 15 pre-pubertal [10 boys], $9.7 \pm 1.5$ years; 11 pubertal [ 6 boys], $14.4 \pm 0.5$ years old) were recruited. At baseline, 3- and 6-months, participants completed an incremental ramp cycle test, isometric handgrip strength test and countermovement jumps, with speed assessed as a measure of performance in swimmers. Principle component analysis (PCA) identified factors that described youth swimmers' physical profile, with linear mixed models subsequently used to determine their interaction with age and maturity on performance.

Results Aerobic fitness and upper body strength were significantly higher in the trained participants, irrespective of maturity status or time-point. Four key factors were identified through PCA (anthropometrics; strength; aerobic capacity; aerobic rate), accounting for $90 \%$ of the between parameter variance. Age exerted a widespread influence on swimming performance predictors, influencing all four factors, whilst maturity only influenced the aerobic factors. The key age of divergence was 13 years. Conclusion Overall, the present study found no evidence of a maturational threshold in the aerobic or strength-related response to training in youth. The influence of age on performance predictors suggests that utilising a single or select group of parameters to inform selection and/or talent identification throughout the dynamic processes of growth and maturation should be avoided.
\end{abstract}

Keywords Aerobic fitness $\cdot$ Strength $\cdot$ Maturity $\cdot$ Pre-pubertal $\cdot$ Pubertal $\cdot$ Power

\section{Introduction}

The popularity of youth sports continues to rise [43], with the age at which children enter training programs continuing to decrease [46], despite this, whether children are "trainable" remains a contentious issue [38]. Indeed, there have been suggestions that, at least in some parameters, there may be a maturational threshold below which training effects are likely to be negligible [30]. Such hypotheses have important implications in the identification of key determinants of performance, implying that these determinants may be

M. A. McNarry

m.mcnarry@swansea.ac.uk

1 School of Sport and Exercise Sciences, Swansea University, Bay Campus, Swansea SA1 8EN, UK

2 School of Human Science, University of Western Australia, Perth 6009, Australia dependent on maturity. However, little research has considered the modulatory role of maturity on the determinants of performance.

Swimmers typically start intensive training pre-puberty [17], with peak performance levels occurring at a relatively young age [13]. Swimming performance is complex and multifaceted, with many factors suggested to influence performance in adults $[2,64]$. However, the applicability of these findings to youth populations is limited, especially given that only 40 of the best 13-14 year-old swimmers are likely to be still ranked in the best 100 at $17-18$ years [56]. The majority of studies investigating the determinants of swimming performance in youth have concentrated on anthropometrical and biomechanical factors, with only a few considering potential bio-energetic determinants, such as aerobic capacity. Duche et al. [14] found cycle-ergometer derived peak oxygen uptake $\left(\mathrm{VO}_{2}\right)$, adjusted for thoracic cross-sectional area, to be a significant predictor of 
performance in pre-pubertal male swimmers, findings supported by more recent studies using $\mathrm{VO}_{2 \text { peak }}$ estimated by backwards extrapolation of data obtained during the first $20 \mathrm{~s}$ of recovery $[29,32]$. However, $\mathrm{VO}_{2 \text { peak }}$ is only one of the determinants of aerobic capacity identified by Whipp et al. [62] and is arguably the least sensitive and relevant to performance [37]. Nonetheless, the relative importance of submaximal parameters of aerobic capacity to performance prediction in youth sport remains to be elucidated.

Interpretation of earlier studies investigating the determinants of swimming performance in youth is limited by their largely cross-sectional nature and reliance on chronological age. Indeed, whilst chronological age has been identified as a performance determinant (e.g. [26, 32]), it is unclear whether this is chronological age per se or rather a reflection of concomitant changes in biological age. As biological maturation does not progress linearly or at the same tempo between, or within (e.g. systems), individuals, chronological and biological age can be significantly dissociated. This may therefore result in considerable maturational differences between athletes within a single chronological age group [57]. Given that talent identification programmes traditionally take place during adolescence, growth and maturation may be a major confounder in the prediction for future talent [59]. Early-maturing individuals are typically characterised by advances in muscular strength, speed and endurance during the time of peak height velocity [35], with these physiological, and associated psychosocial, advantages not only favouring the selection of early-maturing individuals [59], but also likely changing the key determinants of performance relative to pre-pubertal athletes.

The purpose of the present study was to determine the modulatory roles of biological maturity and age on the predictors of performance in youth swimmers. Secondary aims of the study were to investigate the stability of these predictors over a 6-month training cycle and to extend our current understanding regarding the presence of a maturational threshold in aerobic, strength and performance parameters in youth.

\section{Methods}

Overall, 28 trained youths (10 pre-pubertal [6 boys], $11.1 \pm 1.8$ years; 18 pubertal [ 8 boys], $15.2 \pm 2.0$ years) who were competing at a regional $(n=6)$ or national standard $(n=22)$ and 26 untrained controls (15 pre-pubertal [10 boys], $9.7 \pm 1.5$ years; 11 pubertal [ 6 boys], $14.4 \pm 0.5$ years) participated. A mean training volume of $10.5 \pm 3.3$ and $16.4 \pm 1.4 \mathrm{~h}$ per week, and a weekly distance of $29,600 \pm 6900$ and $42,400 \pm 5600 \mathrm{~m}$, was reported for prepubertal and pubertal swimmers, respectively. Following ethical approval, written informed consent and assent were provided by parents and participants, respectively. The study conformed to the Declaration of Helsinki. This was an observational study with all measures were assessed at baseline, mid (3-months) and post a 6-month macro-cycle within the participant's normal training regime. All participants were familiarised with the lab-based measures prior to completing them.

Standing and sitting stature, body mass and waist circumference were measured to the nearest $0.1 \mathrm{~cm}, 0.1 \mathrm{~kg}$ and $0.1 \mathrm{~cm}$, using a stadiometer (Model 213, SECA, Germany), electronic scales (Model 899, SECA, Germany) and a standard anthropometric tape measure (Model 203, SECA, Germany), respectively. Maturity offset was estimated according to Mirwald et al. [44] and classified as "pre-pubertal" or "pubertal" when the maturity offset was $<-1$ years or $>-1$ years, respectively.

Following the determination of hand grip span, three maximal handgrip strength tests per hand were completed interspersed with $30 \mathrm{~s}$ rest (TKK Model 5001, Takei, Japan). The TKK dynamometer has been associated with a lower systematic error and the highest criterion-related validity and reliability for maximal, isometric handgrip strength measurements [18]. The mean score was taken from both hands, without considering hand dominance. Subsequently, a portable force platform (Model 92866AA, Kistler Instruments Ltd, UK) was used to conduct three repeated countermovement jumps (CMJ) according to standard methods [28], with the best performance taken forward for the analysis of peak and mean power. This CMJ technique has been deemed valid and reliable in paediatric populations [28] for the determination of lower limb explosive power output.

Finally, participants completed an incremental ramp test on an electronically braked paediatric cycle ergometer (VIAsprint 150P, Ergoline, Germay) to volitional exhaustion. Following a 3-min warm-up with no additional external load, the resistance progressively increased at a pre-determined rate of $20-30 \mathrm{~W} / \mathrm{min}$ according to age and perceived fitness, with the same ramp rate used at all timepoints. Participants were instructed to maintain a cadence of 70-80 revolutions per minute (rpm) throughout the test, with maximal effort determined by a consistent reduction in cadence below $60 \mathrm{rpm}$ for $5 \mathrm{~s}$, despite strong verbal encouragement. The peak workrate was defined as the highest attained at the point of test termination. Subsequently, participants completed a supramaximal validation bout at $110 \%$ of the peak workrate to verify a maximal effort. Breathby-breath gas exchange was measured using an online gas analyser (Oxycon Mobile, Viasys Healthcare, Germany), calibrated using gases of known concentrations, with the turbine volume transducer calibrated using a 3-L syringe (Hans Rudolph, Kansas City, MO, USA). During the incremental ramp test, stroke volume (SV) and heart rate (HR) 
were measured and recorded via a bioelectrical impedance device (PF-05 Lab1, Manatec Biomedical, France), with cardiac output ( $\dot{\mathrm{Q}})$ subsequently estimated. Surface monitor electrodes (3M Red Dot, USA) were positioned according to the recommendations of Welsman et al. [61]. This protocol has been reported to be reliable in youth [61] and the Physioflow has been shown to provide clinically acceptable measures during rest and exercise [9].

On a separate day, swimming performance was assessed by $3 \times 25 \mathrm{~m}$ frontcrawl sprints at maximum effort from an underwater streamlined push ( $5 \mathrm{~m}$ maximum), with 2-min of active, followed by 2-min of passive, recovery in between. The best performance was used for subsequent analyses.

\section{Data Analysis}

Gas exchange data during the incremental test were interpolated to $1 \mathrm{~s}$ intervals and peak $\mathrm{VO}_{2}, \mathrm{SV}$ and $\mathrm{Q}$ taken as the highest $10 \mathrm{~s}$ moving average. The influence of body size was accounted for using analysis of covariance (ANCOVA) on $\log$ transformed data to determine the allometric relationship between body mass and peak $\mathrm{VO}_{2}$ and peak and mean power derived from the countermovement jump and between body surface area and peak SV and Q. Common allometric exponents were confirmed for all groups and power function ratios $\left(\mathrm{Y} / \mathrm{X}^{\mathrm{b}}\right)$ were computed. Body surface area was calculated according to the equations of Haycock et al. [25]. The gas exchange threshold (GET) was determined from the incremental ramp test by the V-slope method [6] and the Mean Response Time (MRT) and gain calculated according to the methods reported by Barstow et al. [3]. Baseline $\mathrm{VO}_{2}$ was taken as the mean of the first $45 \mathrm{~s}$ of the last minute prior to the increase in workrate.

A paired samples $t$ test was used to compare the $\mathrm{VO}_{2 \text { peak }}$ achieved during the incremental ramp and supramaximal validation bout. Subsequently, mixed linear regression models with a random intercept to account for the nested nature of the data were used to determine the overall effects of time and group (training or control), age, maturity and sex, and their interactions, on the aerobic, and upper and lower body strength responses. Planned contrasts identified the specific location of significant main effects or interactions. Principal component analysis (PCA) was conducted to identify clustered strength, aerobic and anthropometric variables, with final estimates of communalities iterated from squared multiple item correlations to convergence. Kaiser's criterion (Eigenvalues $\geq 1.0$ ), together with Cattell's scree test, were used to determine the number of underlying factors, with an orthogonal varimax rotation performed on the principal components. Further mixed linear regression models with a random intercept were used to determine the overall effect of strength, aerobic and anthropometric variables on swimming performance. To determine whether age and/or maturity moderated the relationship with performance, interaction terms were included in the models and sex was controlled for. All statistical analyses were conducted using Stata v.13 (StataCorp LP, USA), with the exception of PCA, which was conducted in SPSS 23.0 (IBM SPSS Statistics, USA). All data are presented as mean \pm standard deviation (SD). Statistical significance was accepted as $P<0.05$.

\section{Results}

At baseline, the trained pre-pubertal participants were significantly taller and heavier than their untrained counterparts (Table 1). There were no anthropometrical differences between the trained and untrained pubertal participants. The pubertal participants were taller and heavier than the pre-pubertal participants, with no interaction between training and maturity status. Weight increased over the 6-months, irrespective of training, pubertal status, or their interaction. There was no significant difference between the $\mathrm{VO}_{2 \text { peak }}$ achieved during the incremental ramp test and the supramaximal validation bout (pre-pubertal: $1.50 \pm 0.47$ vs. $1.48 \pm 0.52 \mathrm{~L} / \mathrm{min}$; pubertal: $2.60 \pm 0.83$ vs. $2.55 \pm 0.72 \mathrm{~L} /$ min; $P>0.05)$.

There was a significant main effect of group $(\beta=0.42$ [95\%CI: $0.15,0.69] \mathrm{L} / \mathrm{min} ; P<0.01)$, maturity $(\beta=2.50$ $[0.22,4.79] \mathrm{L} / \mathrm{min} ; P=0.03)$ and age $(\beta=0.17[0.04$, 0.29 ] $\mathrm{L} / \mathrm{min} ; P=0.01$ ) on $\mathrm{VO}_{2 \text { peak }}$, all of which were maintained when $\mathrm{VO}_{2 \text { peak }}$ was allometrically scaled for body
Table 1 Participant descriptives at baseline according to maturity and training status

\begin{tabular}{lrrrrr}
\hline Anthropometries & \multicolumn{2}{l}{ Pre-pubertal } & & \multicolumn{2}{l}{ Pubertal } \\
\cline { 2 - 3 } \cline { 5 - 6 } & \multicolumn{1}{c}{ Trained } & Untrained & & Trained & Untrained \\
\hline Age (years) & $11.3 \pm 1.6$ & $9.7 \pm 1.5$ & & $14.8 \pm 1.6$ & $14.4 \pm 0.5$ \\
Height (cm) & $149.6 \pm 8.1$ & $135.5 \pm 8.2^{*}$ & & $169.4 \pm 8.6^{\dagger}$ & $165.9 \pm 9.7^{\dagger}$ \\
Body mass (kg) & $40.5 \pm 8.4$ & $31.4 \pm 6.9^{*}$ & & $66.3 \pm 9.3^{\dagger}$ & $61.9 \pm 14.5^{\dagger}$ \\
Waist circumference (cm) & $65.6 \pm 6.1$ & $61.6 \pm 5.3$ & & $77.5 \pm 6.0^{\dagger}$ & $76.3 \pm 10.4^{\dagger}$ \\
\hline
\end{tabular}

Values are means \pm SD

*Significant difference between trained and untrained within a maturity group, $P<0.05$

${ }^{\dagger}$ Significant difference within trained or untrained between maturity groups, $P<0.05$ 
mass. Whilst there was no effect of time or sex, there was a significant interaction between maturity and group for $\mathrm{VO}_{2 \text { peak }}(\beta=0.55[0.18,0.92] \mathrm{L} / \mathrm{min} ; P<0.01)$, reflecting a greater magnitude of training-related differences in the pubertal than pre-pubertal participants. An interaction between maturity, sex and age was also found for $\mathrm{VO}_{2 \text { peak }}$ ( $\beta=0.26[0.03,0.49] \mathrm{L} / \mathrm{min} ; P=0.03$ ), reflecting similar linear increases in $\mathrm{VO}_{2 \text { peak }}$ with age in the pre-pubertal children, regardless of sex, and pubertal boys, but no change with age in the pubertal girls.

Although no main or interaction effects were evident with regards to the MRT, a main effect of group was evident for both the GET $(\beta=0.26[0.07,0.45] \mathrm{L} / \mathrm{min}$; $P<0.01)$ and gain $\left(\beta=1.77[0.51,3.03] \mathrm{O}_{2} \mathrm{~mL} / \mathrm{W} / \mathrm{min}\right.$; $P<0.01$ ), which were both significantly higher in the trained participants (Table 2). In accord with $\mathrm{VO}_{2 \text { peak }}$, there was a significant interaction between group and maturity, with a greater magnitude of training-related differences in the GET of the pubertal than pre-pubertal participants $(\beta=0.27[0.02,0.52] \mathrm{L} / \mathrm{min} ; P=0.04)$. Whilst there was no effect of time on the GET, there was a main effect of time on the gain, with a lower gain at both 3-months $\left(\beta=-1.53[-2.67,0.39] \mathrm{O}_{2} \mathrm{~mL} / \mathrm{W} / \mathrm{min}\right.$; $P=0.01)$ and 6-months time-points $(\beta=-1.61[-2.81$, $\left.0.42] \mathrm{O}_{2} \mathrm{~mL} / \mathrm{W} / \mathrm{min} ; P=0.01\right)$. There was no interaction between time and group, but a significant interaction was evident between time and maturity status such that the gain was consistently higher in the pubertal than pre-pubertal participants, except for at baseline.

A main effect of group was only evident on handgrip strength $(\beta=4.85[1.1,8.55] \mathrm{kg} ; P=0.01)$, which was significantly higher in the trained participants, with no effect of maturity or time on handgrip strength or CMJ performance (Table 3). Age was associated with both peak $(\beta=148.8$ $[42.6,255.1] \mathrm{W} ; P<0.01)$ and mean $(\beta=13.6[1.8,25.4]$ $\mathrm{W} ; P=0.02) \mathrm{CMJ}$ performance, but not handgrip strength. There was a significant interaction between maturity and sex on handgrip strength ( $\beta=52.5[7.3,97.7] \mathrm{kg} ; P<0.01)$, peak $(\beta=5810[2911,8709] \mathrm{W} ; P<0.01)$ and mean $(\beta=612.1$ [285.2, 939.0] W; $P<0.01)$ CMJ performance, with a greater magnitude of difference between pre-pubertal and pubertal boys than girls, as well as an interaction between maturity, sex and age on all the strength parameters [handgrip strength: $(\beta=3.8[0.5,7.0] \mathrm{kg} ; P=0.02)$; peak CMJ: $(\beta=433.5[224.7,642.3] \mathrm{W} ; P<0.01)$; mean CMJ: $(\beta=43.6$ [20.2, 67.1] W; $P<0.01)]$. Specifically, for all strength parameters, the linear increase with age was steeper in pubertal boys than any other group, with pre-pubertal children and pubertal girls all demonstrating a similar, more modest, progressive increase.
Table 2 Aerobic responses in trained and untrained youth across the 6-month training period according to maturity and training status

\begin{tabular}{|c|c|c|c|c|c|c|}
\hline \multirow[t]{2}{*}{ Aerobic factors } & \multicolumn{2}{|l|}{ Baseline } & \multicolumn{2}{|l|}{ 3-months } & \multicolumn{2}{|l|}{ 6-months } \\
\hline & Trained & Untrained & Trained & Untrained & Trained & Untrained \\
\hline \multicolumn{7}{|l|}{ Pre-pubertal } \\
\hline $\mathrm{VO}_{2 \text { peak }}(\mathrm{L} / \mathrm{min})$ & $1.93 \pm 0.38$ & $1.27 \pm 0.32$ & $1.84 \pm 0.40$ & $1.19 \pm 0.28$ & $1.83 \pm 0.43$ & $1.16 \pm 0.18$ \\
\hline $\mathrm{VO}_{2 \text { peak }}(\mathrm{mL} / \mathrm{kg} / \mathrm{min})$ & $49.1 \pm 7.2$ & $40.2 \pm 5.5$ & $45.2 \pm 6.6$ & $37.1 \pm 5.8$ & $46.1 \pm 6.9$ & $36.1 \pm 6.7$ \\
\hline $\mathrm{VO}_{2 \text { peak }}\left(\mathrm{mL} / \mathrm{kg}^{\mathrm{b}} / \mathrm{min}\right)$ & $95.0 \pm 13.2$ & $74.5 \pm 10.5$ & $88.0 \pm 11.5$ & $69.0 \pm 10.8$ & $74.5 \pm 10.5$ & $67.3 \pm 10.8$ \\
\hline GET (L/min) & $1.12 \pm 0.24$ & $0.79 \pm 0.19$ & $1.04 \pm 0.21$ & $0.78 \pm 0.19$ & $1.05 \pm 0.18$ & $0.70 \pm 0.12$ \\
\hline GET $\left(\% V_{2 \text { peak }}\right)$ & $58 \pm 6$ & $63 \pm 8$ & $57 \pm 6$ & $62 \pm 8$ & $58 \pm 7$ & $59 \pm 6$ \\
\hline MRT (s) & $66 \pm 13$ & $59 \pm 17$ & $66 \pm 13$ & $68 \pm 15$ & $64 \pm 7$ & $56 \pm 15$ \\
\hline Gain $\left(\mathrm{O}_{2}, \mathrm{~mL} / \mathrm{W}\right)$ & $10.2 \pm 1.4$ & $8.8 \pm 2.1$ & $8.7 \pm 1.6$ & $8.4 \pm 3.2$ & $9.0 \pm 1.0$ & $8.5 \pm 1.3$ \\
\hline $25 \mathrm{~m}$ performance $(\mathrm{s})$ & $16.9 \pm 2.0$ & & $17.4 \pm 1.9$ & & $17.3 \pm 2.3$ & \\
\hline \multicolumn{7}{|l|}{ Pubertal } \\
\hline $\mathrm{VO}_{2 \text { peak }}(\mathrm{L} / \mathrm{min})$ & $3.07 \pm 0.73$ & $2.07 \pm 0.38$ & $2.98 \pm 0.76$ & $1.98 \pm 0.48$ & $3.40 \pm 0.87$ & $2.09 \pm 0.44$ \\
\hline $\mathrm{VO}_{2 \text { peak }}(\mathrm{mL} / \mathrm{kg} / \mathrm{min})$ & $46.0 \pm 7.1$ & $34.6 \pm 8.1$ & $45.0 \pm 7.6$ & $32.8 \pm 8.0$ & $50.0 \pm 11.9$ & $31.2 \pm 6.8$ \\
\hline $\mathrm{VO}_{2 \text { peak }}\left(\mathrm{mL} / \mathrm{kg}^{\mathrm{b}} / \mathrm{min}\right)$ & $97.8 \pm 16.0$ & $72.0 \pm 15.3$ & $95.8 \pm 17.2$ & $68.5 \pm 15.9$ & $106.7 \pm 25.4$ & $66.4 \pm 15.9$ \\
\hline GET (L/min) & $1.70 \pm 0.43$ & $1.18 \pm 0.18$ & $1.62 \pm 0.46$ & $1.19 \pm 0.28$ & $1.87 \pm 0.49$ & $1.22 \pm 0.23$ \\
\hline $\operatorname{GET}\left(\% \mathrm{VO}_{2 \text { peak }}\right)$ & $56 \pm 9$ & $57 \pm 5$ & $55 \pm 9$ & $60 \pm 5$ & $55 \pm 8$ & $59 \pm 11$ \\
\hline MRT (s) & $65 \pm 19$ & $64 \pm 8$ & $66 \pm 11$ & $65 \pm 2$ & $59 \pm 13$ & $52 \pm 20$ \\
\hline Gain $\left(\mathrm{O}_{2}, \mathrm{~mL} / \mathrm{W}\right)$ & $8.9 \pm 1.2$ & $8.6 \pm 0.9$ & $8.9 \pm 0.8$ & $9.2 \pm 1.7$ & $9.2 \pm 1.1$ & $9.1 \pm 1.1$ \\
\hline 25 m Performance (s) & $14.1 \pm 1.2$ & & $14.6 \pm 1.2$ & & $14.6 \pm 1.2$ & \\
\hline
\end{tabular}

Values are means $\pm \mathrm{SD}$

$V O_{2}$ oxygen uptake, GET gas exchange threshold, $M R T$ mean response time, $b$ population specific power function ratio 
Table 3 Power and isometric handgrip strength responses in trained and untrained youth across the 6-month training period according to maturity and training status

\begin{tabular}{|c|c|c|c|c|c|c|}
\hline \multirow[t]{2}{*}{ Factors } & \multicolumn{2}{|l|}{ Baseline } & \multicolumn{2}{|l|}{ 3-months } & \multicolumn{2}{|l|}{ 6-months } \\
\hline & Trained & Untrained & Trained & $\overline{\text { Untrained }}$ & Trained & Untrained \\
\hline \multicolumn{7}{|l|}{ Pre-pubertal } \\
\hline $\mathrm{PP}(\mathrm{W})$ & $1350 \pm 361$ & $938 \pm 262$ & $1357 \pm 366$ & $962 \pm 272$ & $1395 \pm 372$ & $970 \pm 247$ \\
\hline $\mathrm{PP}(\mathrm{W} / \mathrm{kg})$ & $32.8 \pm 4.2$ & $29.8 \pm 5.6$ & $34.0 \pm 4.5$ & $30.3 \pm 5.7$ & $33.7 \pm 4.5$ & $30.0 \pm 5.1$ \\
\hline $\mathrm{PP}\left(\mathrm{W} / \mathrm{kg}^{\mathrm{b}}\right)$ & $13.3 \pm 2.1$ & $12.8 \pm 2.5$ & $13.3 \pm 2.1$ & $12.9 \pm 2.5$ & $13.4 \pm 2.2$ & $12.7 \pm 2.4$ \\
\hline $\mathrm{MP}(\mathrm{W})$ & $104 \pm 30$ & $82 \pm 34$ & $116 \pm 38$ & $87 \pm 35$ & $116 \pm 39$ & $86 \pm 34$ \\
\hline MP (W/kg) & $0.7 \pm 0.2$ & $0.6 \pm 0.2$ & $0.8 \pm 0.2$ & $0.6 \pm 0.2$ & $0.7 \pm 0.2$ & $0.6 \pm 0.2$ \\
\hline MP (W/kg) & $1.4 \pm 0.2$ & $1.5 \pm 0.4$ & $1.5 \pm 0.5$ & $1.5 \pm 0.6$ & $1.5 \pm 0.4$ & $1.5 \pm 0.8$ \\
\hline IHS (kg) & $18.6 \pm 3.6$ & $11.0 \pm 3.4$ & $17.6 \pm 4.3$ & $10.6 \pm 3.1$ & $18.8 \pm 4.0$ & $10.8 \pm 3.3$ \\
\hline \multicolumn{7}{|l|}{ Pubertal } \\
\hline $\mathrm{PP}(\mathrm{W})$ & $2774 \pm 639$ & $2059 \pm 540$ & $2776 \pm 689$ & $2177 \pm 515$ & $2559 \pm 626$ & $2307 \pm 410$ \\
\hline $\mathrm{PP}(\mathrm{W} / \mathrm{kg})$ & $38.8 \pm 4.7$ & $33.4 \pm 6.2$ & $40.4 \pm 6.9$ & $35.7 \pm 5.6$ & $38.8 \pm 5.8$ & $34.4 \pm 5.3$ \\
\hline $\mathrm{PP}\left(\mathrm{W} / \mathrm{kg}^{\mathrm{b}}\right)$ & $13.8 \pm 1.7$ & $12.2 \pm 2.3$ & $14.2 \pm 1.7$ & $12.9 \pm 2.2$ & $13.8 \pm 1.8$ & $12.3 \pm 1.9$ \\
\hline $\mathrm{MP}(\mathrm{W})$ & $213 \pm 53$ & $168 \pm 44$ & $221 \pm 84$ & $183 \pm 57$ & $198 \pm 74$ & $191 \pm 69$ \\
\hline $\mathrm{MP}(\mathrm{W} / \mathrm{kg})$ & $1.2 \pm 0.3$ & $1.0 \pm 0.3$ & $1.3 \pm 0.5$ & $1.1 \pm 0.3$ & $1.2 \pm 0.5$ & $1.1 \pm 0.5$ \\
\hline $\mathrm{MP}\left(\mathrm{W} / \mathrm{kg}^{\mathrm{b}}\right)$ & $1.5 \pm 0.3$ & $1.4 \pm 0.3$ & $1.6 \pm 0.4$ & $1.5 \pm 0.4$ & $1.5 \pm 0.4$ & $1.5 \pm 0.5$ \\
\hline IHS (kg) & $31.6 \pm 7.8$ & $24.0 \pm 6.0$ & $33.3 \pm 8.7$ & $23.7 \pm 6.5$ & $30.9 \pm 7.6$ & $24.7 \pm 9.0$ \\
\hline
\end{tabular}

Values are means $\pm \mathrm{SD}$

$P P$ peak power, $M P$ mean power, $I H S$ isometric handgrip strength, $b$ population specific power function ratio

\section{Principal Component Analysis}

Three separate PCAs were performed for strength, anthropometric and aerobic data. One factor was extracted for strength, one for anthropometric and two for aerobic data (labelled aerobic capacity and aerobic rate), accounting for $94 \%, 90 \%$ and $69 \%$ of the common variance between parameters, with factor loadings ranging from 0.96 to $0.98,0.92-0.98$ and $0.44-0.92$, respectively (Table 4). The summed scores for each factor, according to time-point, are shown in Table 5.

\section{Moderation Analysis}

Mixed models were used to determine whether age or maturity moderated the relationship between strength, aerobic and anthropometric factors, and performance, when sex was controlled for. Three-way interaction terms of time*factor*age or time*factor*maturity were included in the models and revealed a more widespread influence of age than maturity on the relationship between potential predictors and performance. Specifically, irrespective of time, increasing strength factor scores were associated with improved performance in those less than 13 years of age but, conversely, poorer performance in those over 13 years. A similar dichotomy, irrespective of time, was observed in the anthropometric factor scores, with increasing anthropometric factor scores beneficially influencing performance in those over, but not less than, 13 years. The influence of aerobic factor scores was
Table 4 Loadings of the strength, anthropometric and aerobic factors identified through principal component analysis

\begin{tabular}{|c|c|c|c|c|}
\hline Factors & Strength & Anthropometric & $\begin{array}{l}\text { Aerobic } \\
\text { capacity }\end{array}$ & Aerobic rate \\
\hline IHS & 0.958 & & & \\
\hline PP & 0.979 & & & \\
\hline MP & 0.963 & & & \\
\hline Height & & 0.982 & & \\
\hline Weight & & 0.949 & & \\
\hline WC & & 0.915 & & \\
\hline $\mathrm{VO}_{2 \text { peak }}$ & & & 0.924 & \\
\hline GET & & & 0.866 & \\
\hline SV & & & 0.905 & \\
\hline$\dot{\mathrm{Q}}$ & & & 0.915 & \\
\hline MRT & & & & 0.792 \\
\hline Gain & & & & 0.440 \\
\hline HR & & & & 0.698 \\
\hline Eigenvalue & 2.8 & 2.7 & 3.5 & 1.4 \\
\hline$\% \mathrm{VE}$ & 93.5 & 90.1 & 49.5 & 19.4 \\
\hline$\% \mathrm{CV}$ & 93.5 & 90.1 & 49.5 & 68.9 \\
\hline
\end{tabular}

$I H S$ isometric handgrip strength, $P P$ peak power, $M P$ mean power, $W C$ waist circumference, $V O_{2}$ oxygen uptake, GET gas exchange threshold, $S V$ stroke volume, $\dot{Q}$ cardiac output, $M R T$ mean response time, $H R$ heart rate, $V E$ variance explained, $C V$ cumulative variance

dependent on time, with the aerobic rate factor only influencing performance at baseline, where higher aerobic rate scores were associated with poorer performance in those less 
Table 5 Mean values (scores) for principle component analysis identified factors according to time-point

\begin{tabular}{lccc}
\hline Factors & Baseline & 3-months & 6-months \\
\hline Strength & 627.4 & 647.1 & 633.3 \\
Anthropometric & 90.0 & 91.1 & 90.0 \\
Aerobic capacity & 29.2 & 27.9 & 32.4 \\
Aerobic rate & 102.4 & 93.5 & 106.1 \\
\hline
\end{tabular}

than 13 years but better performance in those over 13 years. Increases in aerobic capacity factor scores were associated with improved performance, irrespective of age, at baseline, but a similar positive relationship was only observed in those less than 13 years at 3- and 6-months. Maturity significantly moderated the relationship between aerobic fitness and performance but not strength or anthropometric factors; whilst improvements in aerobic capacity factor scores were associated with improved performance in pre-pubertal swimmers at all time-points (albeit marginally at 6-months), a similar relationship was only evident at 3-and 6-months in pubertal swimmers. For aerobic rate, little influence of increasing factors scores was evident in pubertal swimmers, irrespective of time, but a strong association was evident between higher scores and poorer performance in pre-pubertal swimmers at baseline.

\section{Discussion}

This is the first study to holistically consider the influence of training and its interaction with maturity on the performance profile of youth swimmers, and the translation of these adaptations to performance. The current findings demonstrate a significant influence of training on maximal and submaximal parameters of aerobic fitness and handgrip strength in both pre-pubertal and pubertal youth. Four key factors were identified through PCA that described the physical profile of youth, with the relationship on swimming performance predominantly moderated by age, rather than maturity.

Despite the increased interest regarding the influence of training on aerobic and strength-related responses of youth $[19,39]$, few studies have considered the influence of training on each response simultaneously [1]. Whilst this could be due to specific sports or types of training predominately influencing either strength or aerobic parameters, swimming is a whole-body sport that necessitates both [1]. Furthermore, muscular strength and cardiorespiratory endurance are both encompassed within the construct of health-related fitness [8], thus questioning the relevance of their consideration in isolation. It is pertinent to note that, however, despite this strong association, the developmental trajectories of strength and aerobic fitness are distinct in both timing and tempo, differing substantially between sexes [48, 60].

In accord with the growing consensus in the literature $[38,40,42]$, trained swimmers were found to demonstrate a superior $\mathrm{VO}_{2 \text { peak }}$, GET and gain, irrespective of maturity status, thereby refuting the notion of a maturational threshold [30]. These aerobic capacity adaptations appear to be related to an enhanced peak SV and, consequently, $\dot{Q}$, which are likely to reflect functional and morphological adaptations to the myocardium [38]. An inverse relationship between oxidative capacity and exercise efficiency has been reported [27], suggesting the lower gain observed in the swimmers in this study may, at least in part, be attributable to an enhanced oxidative capacity. Indeed, early muscle biopsy work in youth found training increased oxidative enzyme activity [16]. In contrast to previous studies [40, 42], however, the magnitude of difference between the trained swimmers and their untrained counterparts was dependent on maturity, with a greater difference evident in the pubertal participants. This finding may be interpreted to reflect a window of increased trainability, as included in many models of long-term athlete development [5], but given that empirical evidence for such a window is lacking [20], we suggest this observation is more likely to be attributable to the longer training history and greater training volume of the pubertal participants. Indeed, the lack of change in any aerobic parameter over the 6-month training period does not support that the pubertal participants were in a phase of accelerated adaptation, although this lack of significant improvement in aerobic fitness could also be related to the consistency in training volume. Further research investigating the dose-response relationship between training and aerobic adaptations, and their interaction with growth and maturity, is warranted.

The greater isometric strength reported in the trained, compared to untrained participants, is congruent with previous research in both pre-pubertal $[31,36,54]$ and pubertal $[10,12]$ youth. However, not all research has reported training-related differences in isometric strength in youth swimmers [11] or that grip strength increased with age in swimmers [23]. These discrepancies may be related to different measures of strength, and thus muscles interrogated, and/ or to different training volumes and compositions between studies. Specifically, inter-study differences in the relative balance of strength and aerobic training components could significantly alter the physiological profile of swimmers [21], although the transferability of strength training to swimming performance largely remains to be elucidated [22]. In contrast to isometric handgrip strength, which has been related to upper body muscular strength [52], no influence of training was manifest in the CMJ performance, irrespective of maturity status. This is congruent with previous research [41], in which a significant effect of training was only evident in the upper body power responses, which is 
unsurprising given that swimming is a predominantly upper body sport [49].

Resistance training programmes are well-evidenced to benefit youth regardless of age or maturity [34], although the transferability of training benefits from more endurancebased sports like swimming to muscular fitness is less well documented. In contrast with reports that the magnitude of absolute strength gains may be greater in adolescents than children [7], there was no interaction between training and maturity on any parameter of absolute or relative upper or lower body strength. The present study, however, did reveal the independent, interactive effects of age, maturity and sex on strength, highlighting the need to account for these parameters when investigating the influence of stimuli such as growth, maturation and/or training. Moreover, given the considerable male bias in the paediatric exercise physiology literature [15], and especially within strength and conditioning-related research [45], the current findings highlight that many of these findings are unlikely to be applicable to girls at comparable ages and maturity stages.

In the first study to consider clustering of potential determinants of swimming performance in youth, PCA revealed four factors, namely an anthropometric factor, a strength factor and two factors related to aerobic fitness which, together, explained $94 \%$ of the common variance. The loading of the parameters of aerobic fitness previously identified by Whipp et al. [62] onto separate factors is of importance, highlighting the commonality in the determinants of the magnitude-based parameters of $\mathrm{VO}_{2 \text { peak }}$ and GET and their distinction from those of the MRT and gain. Indeed, these loadings demonstrate that these parameters reflect different physiological constructs and reinforces the utility of considering the entire spectrum of aerobic fitness and not solely relying on $\mathrm{VO}_{2 \text { peak }}$. Moreover, the influence of all four factors on performance was moderated by age, with 13 years being a key age of divergence. This apparent influence of age may reflect other training and developmental factors not accounted for in the present study, such as significant increases in training volume or cognitive or biomechanical advances. Nonetheless, the present study highlights that performance predictors change throughout the dynamic process of ageing and that seeking to identify a single or select group of parameters to inform training and/or talent identification is likely to lead to erroneous conclusions.

Whilst research has reported that anthropometric parameters were key determinants of swimming performance in youth [47, 50, 55], Geladas et al. [24] found that the specific anthropometric parameters depended on sex. The dichotomous influence on performance of the anthropometric factor in the current study may reflect the independent influence of age and growth on the underlying parameters. Specifically, in those aged less than 13 years, increases in clustered anthropometric scores are likely to predominantly reflect increases in height, which may actually cause temporary detriments in performance whilst biomechanical and technical aspects adjust, given that substantial gains in muscle mass are only made later in growth [4], this may contribute to the beneficial effect of increasing anthropometrics on performance only being manifest above this age threshold. Indeed, such muscle gains would be anticipated to have resulted in a similar dichotomy in the influence of strength on performance, but the reverse was evident in the current study, with strength a key predictor of performance below, but not above, 13 years of age. Garrido et al. [23] also found no consistent relationship between grip strength and performance in youth swimmers. The explanation for this contradictory result is currently unclear but may be related to the specific performance measure utilised, it could be hypothesised that the role of strength would have been more evident in longer duration swims or those that involved turns.

The present findings extend earlier studies, which similarly found $\mathrm{VO}_{2 \text { peak }}$ to be a key determinant of performance in youth swimmers $[14,26,29,32]$, to consider submaximal aerobic fitness parameters as well as the concomitant influences of age and maturation. As previously highlighted [51], fundamental changes occur in a variety of parameters, including anthropometrical, physiological, and mechanical factors, from pre-puberty to puberty, though only one study has previously included both pre-pubertal and pubertal participants [29]. The greater importance of aerobic factors in those less than 13 years of age in the current study could be attributed to their under-developed technical abilities [14] or glycolytic capacity [53]. Specifically, the metabolic cost of swimming and blood lactate accumulation have been shown to similarly increase with age $[29,51]$, potentially due to changes that occur with growth, such as muscle fibre type characteristics, proportions and distributions, hormonal effects or neuromotor maturation [58]. When considering the relative contribution of metabolic pathways to the present results, it is pertinent to note the duration of the performance measure used $(\sim 15 \mathrm{~s})$, as well as the general classification of the maximal and sub-maximal parameters of aerobic fitness as measures of endurance fitness. This dissociation may explain the dichotomous results according to age, with a longer performance measure, as used in previous studies $[14,29]$, potentially increasing the importance of the aerobic fitness parameters. Finally, it is important to be cognisant of suggestions that the value of measuring bio-energetic parameters during swimming, rather than through non-specific exercise modalities, increases with age and performance level, with technical ability playing an increasingly important role in determining performance in elite swimmers [33].

There are several limitations that must be considered when interpreting the present results. Whilst this is the first study to consider the influence of age and maturity on 
performance determinants in youth swimmers, the sample size limited potential comparisons, including those associated with sex. Also, no biomechanical factors such as stroke rate and length, which have previously been reported to be important predictors of performance in youth swimmers were obtained ([47, 63]). Finally, although multiple timepoints provided an insight into the influence of training, it would have increased the interpretation of this study if these time-points had spanned the entire training season, accounting for adherence, rather than one macro-cycle within it.

In conclusion, the present study found no evidence of a maturational threshold in the aerobic or strength-related response to training in youth. Four key factors (anthropometrics; strength; aerobic capacity; aerobic rate) were identified that described the physical profile of youth swimmers, with the role of these factors in determining performance predominately modulated by chronological, rather than biological, age. This influence of age on performance predictors suggests that utilising a single or select group of parameters to inform selection and/or talent identification throughout the dynamic processes of growth and maturation should be avoided.

Acknowledgements The authors would like to express their gratitude to Sally Carter who assisted with the data collection, as well as the children and adolescents and swimming club.

Author contributions All authors conceived and designed the study. JB collected the data which was analysed and interpreted by LL and MAM. All authors contributed to manuscript preparation, revisions and approved the final version.

Funding Not applicable.

Availability of data and material As this data was taken from one local swimming club, anonymity could not be ensured if the data were made available.

\section{Compliance with ethical standards}

Conflict of interest The authors do not have any conflict of interest to disclose.

Informed consent Written informed assent and consent was obtained from participants and their parent/guardian, respectively.

Open Access This article is licensed under a Creative Commons Attribution 4.0 International License, which permits use, sharing, adaptation, distribution and reproduction in any medium or format, as long as you give appropriate credit to the original author(s) and the source, provide a link to the Creative Commons licence, and indicate if changes were made. The images or other third party material in this article are included in the article's Creative Commons licence, unless indicated otherwise in a credit line to the material. If material is not included in the article's Creative Commons licence and your intended use is not permitted by statutory regulation or exceeds the permitted use, you will need to obtain permission directly from the copyright holder. To view a copy of this licence, visit http://creativecommons.org/licenses/by/4.0/.

\section{References}

1. Aspenes S, Kjendlie PL, Hoff J, Helgerud J. Combined strength and endurance training in competitive swimmers. J Sports Sci Med. 2009;8(3):357-65.

2. Barbosa TM, Bragada JA, Reis VM, Marinho DA, Carvalho C, Silva AJ. Energetics and biomechanics as determining factors of swimming performance: updating the state of the art. J Sci Med Sport. 2010;13(2):262-9. https://doi.org/10.1016/j.jsams .2009.01.003.

3. Barstow TJ, Scremin AM, Mutton DL, Kunkel CF, Cagle TG, Whipp BJ. Peak and kinetic cardiorespiratory responses during arm and leg exercise in patients with spinal cord injury. Spinal Cord. 2000;38(6):340-5.

4. Baxter-Jones A. Growth and maturation. In: Armstrong N, van Mechelen W, editors. Oxford textbook of children's sport and exercise medicine. Oxford: Oxford University Press; 2017. p. 13-23.

5. Bayli I, Hamiliton A. Long-term athlete development: trainability in childhood and adolescence: windows of opportunity, optional trainability. Victoria: National Coaching Institute and Advanced Training and Performance; 2004.

6. Beaver WL, Wasserman K, Whipp BJ. A new method for detecting anaerobic threshold by gas-exchange. J Appl Physiol. 1986;60(6):2020-7.

7. Behringer M, vom Heede A, Yue Z, Mester J. Effects of resistance training in children and adolescents: a meta-analysis. Pediatrics. 2010;126(5):e1199-210. https://doi.org/10.1542/ peds.2010-0445.

8. Caspersen CJ, Powell KE, Christenson GM. Physical activity, exercise, and physical fitness: definitions and distinctions for health-related research. Public health Rep. 1985;100(2):126-31.

9. Charloux A,Lonsdorfer-Wolf E, Richard R, Lampert E, OswaldMammosser M, Mettauer B, Geny B, Lonsdorfer J. A new impedance cardiograph device for the non-invasive evaluation of cardiac output at rest and during exercise: comparison with the "direct" Fick method. Eur J Appl Physiol. 2000;82(4):313-20.

10. Christou M, Smilios I, Sotiropoulos K, Volaklis K, Pilianidis $\mathrm{T}$, Tokmakidis SP. Effects of resistance training on the physical capacities of adolescent soccer players. J Strength Cond Res. 2006;20(4):783-91. https://doi.org/10.1519/r-17254.1.

11. Clarke DH, Vaccaro P. The effect of swimming training on muscular performance and body composition in children. Res Q. 1979;50(1):9-17.

12. DeRenne C, Hetzler RK, Buxton BP, Ho KW. Effects of training frequency on strength maintenance in pubescent baseball players. J Strength Cond Res. 1996;10(1):8-14.

13. Dormehl SJ, Robertson SJ, Williams CA. How confident can we be in modelling female swimming performance in adolescence? Sports (Basel). 2016;4(1):16. https://doi.org/10.3390/ sports4010016.

14. Duché P, Falgairette G, Bedu M, Lac G, Robert A, Coudert J. Analysis of performance of prepubertal swimmers assessed from anthropometric and bio-energetic characteristics. Eur J Appl Physiol Occup Physiol. 1993;66(5):467-71.

15. Eliakim A, Falk B, Armstrong N, Baptista F, Behm DG, Dror N, Faigenbaum AD, Janz KF, Jürimäe J, McGowan AL, Nemet D, Pianosi PT, Pontifex MB, Radom-Aizik S, Rowland T, Rowlands AV. Expert's choice: 2018's most exciting research in the field of pediatric exercise science. Ped Exerc Sci. 2019;31(1):1-27. https ://doi.org/10.1123/pes.2019-0010.

16. Eriksson BO, Gollnick PD, Saltin B. Muscle metabolism and enzyme activities after training in boys 11-13 years old. Acta Physiol Scand. 1973;87(4):485-97. 
17. Erlandson MC, Sherar LB, Mirwald RL, Maffulli N, BaxterJones ADG. Growth and maturation of adolescent female gymnasts, swimmers, and tennis players. Med Sci Sports Exerc. 2008;40(1):34-42. https://doi.org/10.1249/mss.0b013e318159667 8.

18. España-Romero V, Ortega FB, Vicente-Rodríguez G, Artero EG, Rey JP, Ruiz JR. Elbow position affects handgrip strength in adolescents: validity and reliability of Jamar DynEx, and TKK dynamometers. J Strength Cond Res. 2010;24(1):272-7. https:// doi.org/10.1519/JSC.0b013e3181b296a5.

19. Faigenbaum AD, Lloyd R. Resistance training. In: Armstrong N, Van Mechelen W, editors. Oxford textbook of children's sport and exercise medicine. 3rd ed. Oxford, UK: Oxford University Press; 2017. p. 493-506.

20. Ford P, Croix MDC, Lloyd R, Meyers R, Moosavi M, Oliver J, Till K, Williams C. The long-term athlete development model: physiological evidence and application. J Sports Sci. 2011;29(4):389-402.

21. Gäbler M, Prieske O, Hortobágyi T, Granacher U. The effects of concurrent strength and endurance training on physical fitness and athletic performance in youth: a systematic review and meta-analysis. Front Physiol. 2018. https://doi.org/10.3389/fphys .2018.01057.

22. Garrido N, Marinho DA, Reis VM, van den Tillaar R, Costa AM, Silva AJ, Marques MC. Does combined dry land strength and aerobic training inhibit performance of young competitive swimmers? J Sports Sci Med. 2010;9(2):300-10.

23. Garrido ND, Silva AJ, Fernandes RJ, Barbosa TM, Costa AM, Marinho DA, Marques MC. High level swimming performance and its relation to non-specific parameters: a cross-sectional study on maximum handgrip isometric strength. Percept Mot Skills. 2012;114(3):936-48. https://doi.org/10.2466/05.10.25. Pms.114.3.936-948.

24. Geladas ND, Nassis GP, Pavlicevic S. Somatic and physical traits affecting sprint swimming performance in young swimmers. Int J Sports Med. 2005;26(2):139-44. https://doi. org/10.1055/s-2004-817862.

25. Haycock GB, Schwartz GJ, Wisotsky DH. Geometric method of measuring body surface area. J Pediatr. 1978;93(1):62-6.

26. Hue O, Antoine-Jonville S, Galy O, Blonc S. Anthropometric and physiological characteristics in young afro-Caribbean swimmers. A preliminary study. Int J Sports Physiol Perform. 2013;8(3):2718. https://doi.org/10.1123/ijspp.8.3.271.

27. Hunter G, Bamman M, Larson-Meyer D, Joanisse D, McCarthy J, Blaudeau T, Newcomer B. Inverse relationship between exercise economy and oxidative capacity in muscle. Eur J Appl Physiol. 2005;94(5-6):558-68. https://doi.org/10.1007/s0042 1-005-1370-z.

28. Jones CM. Developing a criterion method for assessing countermovement jump variables in children aged 7-11 years. Swansea: Swansea University; 2018.

29. Jurimae J, Haljaste K, Cicchella A, Latt E, Purge P, Leppik A, Jurimae T. Analysis of swimming performance from physical, physiological, and biomechanical parameters in young swimmers. Pediatr Exerc Sci. 2007;19(1):70-81.

30. Katch VL. Physical conditioning of children. J Adols Health. 1983;3(4):241-6.

31. Keiner M, Sander A, Wirth K, Caruso O, Immesberger P, Zawieja $M$. Strength performance in youth: trainability of adolescents and children in the back and front squats. J Strength Cond Res. 2013;27(2):357-62. https://doi.org/10.1519/JSC.0b013e3182 $576 \mathrm{fbf}$.

32. Lätt E, Jürimäe J, Haljaste K, Cicchella A, Purge P, Jürimäe T. Physical Development and Swimming Performance During Biological Maturation in Young Female Swimmers. Coll Antropol. 2009;33(1):117-22.
33. Lavoie JM, Montpetit RR. Applied physiology of swimming. Sports Med. 1986;3:165-89. https://doi.org/10.2165/00007256198603030-00002.

34. Lloyd RS, Faigenbaum AD, Stone MH, Oliver JL, Jeffreys I, Moody JA, Brewer C, Pierce KC, McCambridge TM, Howard R, Herrington L, Hainline B, Micheli LJ, Jaques R, Kraemer WJ, McBride MG, Best TM, Chu DA, Alvar BA, Myer GD. Position statement on youth resistance training: the 2014 International Consensus. Br J Sports Med. 2014;48(7):498-505. https://doi. org/10.1136/bjsports-2013-092952.

35. Malina R, Bouchard C, Bar-Or O. Growth, maturation, and physical activity. 2nd ed. Champaign: Human Kinetics; 2004.

36. Marta C, Marinho D, Izquierdo M, Marques M. Differentiating maturational influence on training-induced strength and endurance adaptations in prepubescent children. Am J Hum Biol. 2014;26(4):469-75. https://doi.org/10.1002/ajhb.22549.

37. Matos N, Winsley RJ. Trainability of young athletes and overtraining. J Sport Sci Med. 2007;6(3):353-67.

38. McNarry M, Jones A. The influence of training status on the aerobic and anaerobic responses to exercise in children: a review. Eur J Sport Sci. 2014;14(S1):S57-S68. https://doi. org/10.1080/17461391.2011.643316.

39. McNarry MA, Armstrong N. Aerobic trainability. In: Armstrong $\mathrm{N}$, van Mechelen W, editors. Oxford textbook of children's sport and exercise medicine. Oxford: Oxford University Press; 2017. p. 465-476.

40. McNarry MA, Mackintosh KA, Stoedefalke K. Longitudinal investigation of training status and cardiopulmonary responses in pre- and early-pubertal children. Eur J Appl Physiol. 2014;114(8):1573-80.

41. McNarry MA, Welsman JR, Jones AM. The influence of training and maturity status on girls' responses to short-term, highintensity upper- and lower-body exercise. Appl Physiol Nutr Met. 2011;36(3):344-52. https://doi.org/10.1139/H11-019.

42. McNarry MA, Welsman JR, Jones AM. Influence of training and maturity status on the cardiopulmonary responses to ramp incremental cycle and upper body exercise in girls. J Appl Physiol. 2011;110(2):375-81. https://doi.org/10.1152/jappl physiol.00988.2010.

43. Merkel DL. Youth sport: positive and negative impact on young athletes. Open Access J Sports Med. 2013;4:151-60. https://doi. org/10.2147/OAJSM.S33556.

44. Mirwald RL, Baxter-Jones AD, Bailey DA, Beunen GP. An assessment of maturity from anthropometric measurements. Med Sci Sport Exerc. 2002;34(4):689-94.

45. Moran J, Clark CCT, Ramirez-Campillo R, Davies MJ, Drury B. A meta-analysis of plyometric training in female youth: its efficacy and shortcomings in the literature. J Strength Cond Res. 2019;33(7):1996-2008. https://doi.org/10.1519/jsc.0000000000 002768 .

46. Myer GD, Lloyd RS, Brent JL, Faigenbaum AD. How young is "too young" to start training? ACSMs Health Fit J. 2013;17(5):14-23. https://doi.org/10.1249/FIT.0b013e3182 a06c59.

47. Nasirzade A, Sadeghi H, Sobhkhiz A, Mohammadian K, Nikouei A, Baghaiyan M, Fattahi A. Multivariate analysis of 200-m front crawl swimming performance in young male swimmers. Acta Bioeng Biomech. 2015;17(3):137-43.

48. Nevill AM, Holder RL, Baxter-Jones A, Round JM, Jones DA. Modeling developmental changes in strength and aerobic power in children. J Appl Physiol. 1998;84(3):1-8.

49. Ogita F, Hara M, Tabata I. Anaerobic capacity and maximal oxygen uptake during arm stroke, leg kicking and whole body swimming. Acta Physiol Scand. 1996;157(4):435-41. 
50. Ostrowska B, Domaradzki J, Ignasiak Z. Factor analysis of anthropometric characteristics in young swimmers aged 11 and 12. Acta Gymnica. 2006;36:59-68.

51. Poujade B, Hautier CA, Rouard A. Determinants of the energy cost of front-crawl swimming in children. Eur J Appl Physiol. 2002;87(1):1-6. https://doi.org/10.1007/s00421-001-0564-2.

52. Ramirez-Velez R, Pena-Ibagon JC, Martinez-Torres J, Tordecilla-Sanders A, Correa-Bautista JE, Lobelo F, Garcia-Hermoso A. Handgrip strength cutoff for cardiometabolic risk index among Colombian children and adolescents: The FUPRECOL Study. Sci Rep. 2017;7:42622. https://doi.org/10.1038/srep4 2622.

53. Ratel S, Blazevich AJ. Are prepubertal children metabolically comparable to well-trained adult endurance athletes? Sports Med. 2017;47(8):1477-85. https://doi.org/10.1007/s40279-016-0671-1.

54. Rians CB, Weltman A, Cahill BR, Janney CA, Tippett SR, Katch FI. Strength training for prepubescent males: is it safe? Am J Sport Med. 1987;15(5):483-9. https://doi.org/10.1177/0363546587 01500510 .

55. Sammoud S, Nevill AM, Negra Y, Bouguezzi R, Chaabene H, Hachana Y. 100-m breaststroke swimming performance in youth swimmers: the predictive value of anthropometrics. Ped Exerc Sci. 2018;30(3):393. https://doi.org/10.1123/pes.2017-0220.

56. Sokolavas G. Analysis of USA swimming's all-time top 100 times. Biomech Med Swim. 2006;6:315-7.

57. Vaeyens R, Lenoir M, Williams AM, Philippaerts RM. Talent identification and development programmes in sport: current models and future directions. Sports Med. 2008;38(9):703-14. https://doi.org/10.2165/00007256-200838090-00001.

58. Van Praagh E. Development of anaerobic function during childhood and adolescence. Pediatr Exerc Sci. 2000;12:150-73.

59. Vandendriessche JB, Vaeyens R, Vandorpe B, Lenoir M, Lefevre J, Philippaerts RM. Biological maturation, morphology, fitness, and motor coordination as part of a selection strategy in the search for international youth soccer players (age 15-16 years). J Sports Sci. 2012;30(15):1695-703. https://doi.org/10.1080/02640 414.2011.652654.

60. Viru A, Loko J, Harro M, Volver A, Laaneots L, Mehis V. Critical periods in the development of performance capacity during childhood and adolescence. Eur J Phys Ed. 1999;4:75-119.

61. Welsman J, Bywater K, Farr C, Welford D, Armstrong N. Reliability of peak $\mathrm{VO}_{2}$ and maximal cardiac output assessed using thoracic bioimpedance in children. Eur J Appl Physiol. 2005;94(3):228-34. https://doi.org/10.1007/s00421-004-1300-5.

62. Whipp BJ, Davis JA, Torres F, Wasserman K. A test to determine parameters of aerobic function during exercise. J Appl Physiol. 1981;50(1):217-21.

63. Zamparo P, Capelli C, Cautero M, Di Nino A. Energy cost of front-crawl swimming at supra-maximal speeds and underwater torque in young swimmers. Eur J Appl Physiol. 2000;83(6):48791. https://doi.org/10.1007/s004210000318.

64. Zamparo P, Cortesi M, Gatta G. The energy cost of swimming and its determinants. Eur J Appl Physiol. 2020;120(1):41-66. https:// doi.org/10.1007/s00421-019-04270-y. 